\title{
Nanotecnología, medicina veterinaria y producción agropecuaria
}

\author{
Coppo, J.A. \\ Cátedra de Fisiología, Facultad de Ciencias Veterinarias, UNNE, Sargento Cabral 2139, Corrientes (3400), \\ Argentina. Tel. 03783-425753. E-mail: jcoppo@vet.unne.edu.ar.
}

\begin{abstract}
Resumen
Coppo, J.A.: Nanotecnología, medicina veterinaria y producción agropecuaria. Rev. vet. 20: 1, 61-71, 2009. La nanotecnología ha sido definida como el arte de manipular la materia, átomo por átomo. Por ello, sus materiales tienen un tamaño entre 1 y 100 nanómetros. En esta revisión se detallan los dispositivos, sustancias y sistemas utilizados por esta ciencia, así como sus alcances y limitaciones. Se describen herramientas como fullerenes, nanotubes, buckyballs, dendrimers, quantum dots, nanoshells y otras, consignando sus usos actuales y posibilidades futuras. Se resaltan las aplicaciones de la nanotecnología en medicina veterinaria, producción animal y otras áreas, con especial énfasis a los sensores, dispensadores, inmunógenos y quimioterápicos disponibles, así como al funcionamiento de dispositivos a escala nanométrica creados para el diagnóstico, tratamiento, monitoreo y trazabilidad de insumos agropecuarios. Se discuten los eventuales riesgos que podrían involucrar estas técnicas. La nanotecnología es hoy una realidad concreta cuyas repercusiones futuras son inmensas y solamente están limitadas por la imaginación y capacidad creativa de los científicos.
\end{abstract}

Palabras clave: nanotecnología, ciencias veterinarias, aplicaciones, perspectivas.

\begin{abstract}
Coppo, J.A.: Nanotechnology, veterinary medicine and agropecuary production. Rev. vet. 20: 1, 61-71,2009. Nanotechnology has been defined as the art of matter manipulation, atom by atom. Therefore, its materials have a size between 1 and 100 nanometers. Devices, substances and systems used by this science, as well as its scopes and limitations, are presented in this review. Tools such as fullerenes, nanotubes, buckyballs, dendrimers, quantum dots, nanoshells and others are described, considering their current uses and future possibilities. Applications of nanotechnology in veterinary medicine, animal production and other areas are detailed with special emphasis on sensors, dispensers, immunogens, and chemotherapic tools available nowadays, as well as mechanisms of nanometrical scale devices designed for diagnosis, treatment, monitoring and traceability of agropecuary supplies. Eventual risks that could involve these techniques are discussed. Nanotechnology is today a reality which future repercussions are immense and only limited by imagination and scientists' creative capacity.
\end{abstract}

Key words: nanotechnology, veterinary sciences, applications, perspectives.

\section{INTRODUCCIÓN}

Todos los libros del mundo podrían caber en la cabeza de un alfiler. Richard Feynman

Definiciones. Nanotecnología es un campo de las ciencias aplicadas dedicado al control y manipulación de la materia (nanomateriales) a una escala menor que un micrómetro (entre 1 y 100 nanómetros), es decir, a nivel de átomos y moléculas. El prefijo "nano" indica no un objeto sino una medida (la mil millonésima parte

Recibido: 4 mayo 2009 / Aceptado: 20 julio 2009 de algo), por ello la nanotecnología se caracteriza por ser un campo esencialmente multidisciplinar cohesionado exclusivamente por la escala de la materia con la que trabaja ${ }^{30}$.

La nanotecnología es el arte de manipular la materia, átomo por átomo. Un nanómetro $(\mathrm{nm})$ es definido como una milmillonésima del metro. Téngase en cuenta que $10.000 \mathrm{~nm}$ es el diámetro de un eritrocito, 1.000 $\mathrm{nm}$ el de una bacteria, $100 \mathrm{~nm}$ el de un virus, $5-50 \mathrm{~nm}$ el de una proteína, $2 \mathrm{~nm}$ el del ADN y $0,1 \mathrm{~nm}$ el de un átomo ${ }^{9,11}$.

Aunque en las investigaciones actuales con frecuencia se hace referencia a la nanotecnología (en forma de motores moleculares, computación cuántica y otras he- 
rramientas), es discutible que tal disciplina sea una realidad concreta hoy en día, pero las repercusiones que acarreará para el futuro son inmensas. Los progresos actuales pueden calificarse más bien de nanociencia, cuerpo de conocimiento que sienta las bases para el futuro desarrollo de una tecnología basada en la manipulación detallada de las estructuras moleculares ${ }^{30}$.

La nanotecnología es el estudio, diseño, creación, síntesis, manipulación controlada y aplicación de sustancias, materiales, aparatos, dispositivos y sistemas funcionales a través del control de la materia a escala nanométrica, esto es átomo por átomo o molécula por molécula, es decir, a la misma escala a la que trabaja la naturaleza. Ello permite atrapar y situar átomos y moléculas en posiciones determinadas y fabricar artefactos con una precisión de unos pocos átomos (téngase en cuenta que $1 \mathrm{~nm}$ equivale aproximadamente a 10 átomos de hidrógeno en línea). De este modo, los científicos pueden adentrarse en el nanomundo y descubrir fenómenos y propiedades de la materia hasta ahora desconocidos, que permiten el desarrollo de numerosas nanoaplicaciones que pueden resultar de una extraordinaria importancia ${ }^{9}$.

El objetivo de este artículo es despertar el interés sobre el impulso que la nanotecnología es capaz de generar en el campo de la medicina veterinaria. Debido a que aquella rama de la ciencia se encuentra en una fase muy temprana de desarrollo, pueden pasar varios años antes de la obtención de resultados significativos, pero como profesionales tenemos que empezar a prepararnos para su utilización. Se afirma que el desarrollo de la nanotecnología tendrá consecuencias extraordinarias para la medicina y la veterinaria, porque cambiará la definición de la enfermedad y la manera en que hacemos el diagnóstico y el tratamiento ${ }^{11}$.

Alcances. Uno de los más increíbles descubrimientos recientes es la capacidad de medir, manipular y organizar la materia a nivel nanométrico ${ }^{11}$. Para comprender el potencial de esta tecnología es clave saber que las propiedades físicas y químicas de la materia cambian a escala nanométrica, lo cual se debe a efectos cuánticos. La conductividad eléctrica, el calor, la resistencia, la elasticidad, la reactividad, entre otras propiedades, se comportan de manera diferente que en los mismos elementos a mayor escala ${ }^{30}$.

La nanotecnología se concibe como "la investiga- j ción y tecnología del desarrollo atómico, molecular y macromolecular en la escala de aproximadamente $1 \mathrm{a}$ 100 nanómetros, para proporcionar una comprensión fundamental de los fenómenos y materiales a nanoescala y crear y utilizar estructuras, dispositivos y sistemas que tienen propiedades y funciones debido a su pequeñez". El término nanomedicina se refiere al uso de máquinas moleculares (como nanobots, sondas, sensores y otras maravillas de la ingeniería) para tratar problemas médicos, así como al empleo de los conocimientos moleculares para mantener y mejorar la salud en escala molecular ${ }^{11}$.
Los aportes de la nanotecnología abarcan la exploración espacial (nanotubos de carbono para cables y estudios cartográficos, robots, naves y ascensores espaciales, tejidos autorreparables), comunicación e informática (sistemas de almacenamiento de datos de muy alta densidad de registro, nuevas tecnologías de visualización a base de plásticos flexibles, semiconductores, nanochips, computación cuántica), sector energético (mejora del almacenamiento y producción de energía, desarrollo de energías alternativas y limpias, energía del hidrógeno, pilas de combustible, dispositivos de ahorro energético), medioambiente (desarrollo de energías, materiales y procesos no contaminantes, depuración y desalinización del agua, detoxificación y prevención de la erosión del suelo, reducción de la extracción de minerales), industria textil (tejidos "inteligentes", autolimpiables, antiolores, antimanchas, reguladores de la temperatura, ignífugos y que cambian de color, eliminación de contaminantes y alérgenos), construcción y arquitectura (nanomateriales más ligeros y resistentes, pinturas especiales, vidrios que repelen la humedad, el polvo y la suciedad, hormigones "inteligentes", materiales autorreparables, superficies antihumedad y antipintadas), electrónica (semiconductores, cables cuánticos, circuitos con nanotubos de carbono), fabricaciones militares, espionaje, industria automovilística, seguridad personal y vial, e incluso deportes ${ }^{9}$.

Países en vías de desarrollo ya destinan importantes recursos a la investigación en nanotecnología. La nanomedicina es una de las áreas que más puede contribuir al avance sostenible del tercer mundo, proporcionando nuevos métodos de diagnóstico y cribaje de enfermedades, así como mejores sistemas para la administración de fármacos y herramientas para la monitorización de algunos parámetros biológicos. Actualmente, alrededor de 40 laboratorios en todo el mundo canalizan grandes cantidades de dinero para la investigación en nanotecnología. Unas 300 empresas tienen el término "nano" en su nombre, aunque todavía hay muy pocos productos en el mercado ${ }^{30}$.

Futuras aplicaciones. Las aplicaciones más prometedoras de la nanotecnología se relacionan con producción agrícola, alimentos transgénicos, procesamiento de alimentos, tratamiento y depuración de aguas, monitorización de la salud, diagnóstico y cribaje de enfermedades, sistemas de administración de fármacos, remediación de la contaminación atmosférica, detección y control de plagas, control de desnutrición en lugares pobres, construcción, almacenamiento, producción y conversión de energía, informática, armamento y sistemas de defensa ${ }^{11,30}$.

Actualmente en el primer mundo ya se pueden adquirir artículos nano tales como sanitarios, componentes electrónicos, pinturas resistentes al rayado, telas antiarrugas o antimanchas y lociones solares, entre otros. El volumen de productos desarrollados mediante nanotecnología es hoy del $0,1 \%$ del total de manufacturas, pero en la próxima década ascenderá al $15 \%$. Se 
estima que tal aumento ocurrirá en áreas como medicina, farmacia, materiales, informática, instrumentos de medición, producción y almacenamiento de energía ${ }^{2}$.

Interdisciplinariedad. La característica fundamental de la nanotecnología es que constituye un ensamblaje interdisciplinar de varios campos de las ciencias naturales que están altamente especializados. Por tanto, los físicos juegan un importante rol no sólo en la construcción del microscopio usado para investigar tales fenómenos, sino también en todas las leyes de la mecánica cuántica. Alcanzar la estructura del material deseado y las configuraciones de ciertos átomos, hacen jugar a la química un papel importante. La ciencia ha alcanzado un punto en el que las fronteras que separan las diferentes disciplinas han empezado a diluirse, y precisamente por esa razón la nanotecnología también se incluye como una tecnología convergente. Una posible lista de disciplinas involucradas sería la siguiente: física, química, bioquímica, biología molecular, electrónica, informática y matemáticas ${ }^{30}$.

La ingeniería de nanosistemas (máquinas a escala nanométrica) opera a nivel molecular, basándose en que los productos manufacturados se construyen a partir de átomos. Las propiedades de estos productos dependen de cómo estén dispuestos esos átomos. Así por ejemplo, si reubicamos los átomos del grafito de la mina del lápiz (compuesto principalmente por carbono) podemos hacer diamantes (carbono puro cristalizado). Si reubicamos los átomos de la arena (compuesta básicamente por sílice) y agregamos algunos elementos extras, se hacen los chips de un ordenador. A partir de los incontables ejemplos encontrados en la biología se sabe que miles de millones de años de retroalimentación evolucionada pueden producir máquinas biológicas sofisticadas y estocásticamente optimizadas. Se tiene la esperanza que los desarrollos en nanotecnología harán posible su construcción a través de procesos más cortos, quizás usando principios biomiméticos ${ }^{9,30}$.

Sinopsis histórica ${ }^{9,11,30}$. Se considera que Richard Feynman (Figura 1) es el padre de la nanociencia. Sus trabajos sobre electrodinámica cuántica le valieron en 1959 el Premio Nobel de Física. Feynman propuso fabricar productos en base a un reordenamiento de átomos y moléculas, concibiendo máquinas que trabajando con átomos individuales podrían consumir poquísima energía y conseguir velocidades asombrosas. En 1956 aquél premio había sido adjudicado a otros pioneros de la manipulación molecular como Bardeen, Brattain y Shockley, inventores del transistor. Hacia la misma época Watson y Crick proponían que la molécula del ADN jugaba un papel clave en la regulación de los procesos del organismo.

Importantes aportes a la nanotecnología molecular fueron realizados por Eric Drexler en la década de 1980, incluyendo la construcción de nanomáquinas hechas de átomos, las cuales eran capaces de construir ellas mismas otros componentes moleculares. En su li-

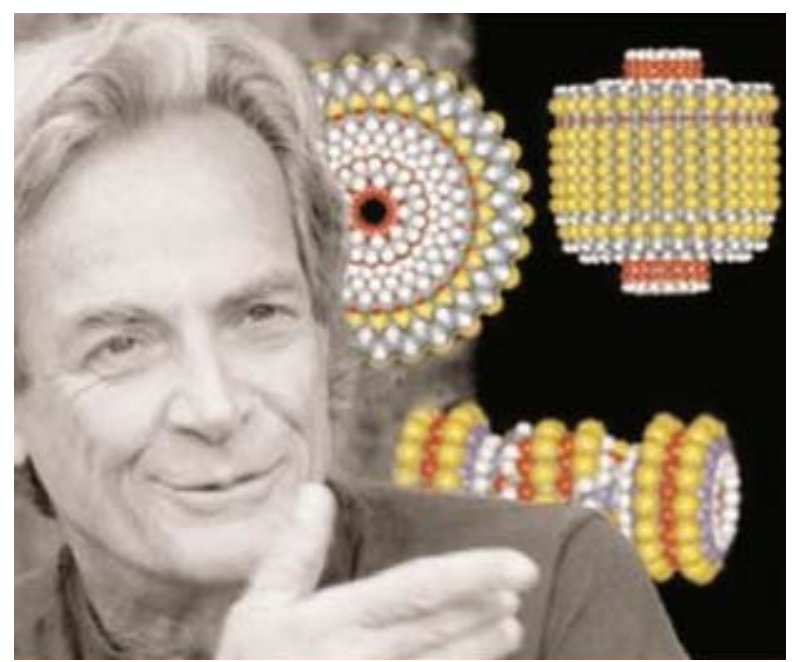

Figura 1. Richard Feynman, pionero de la nanotecnología.

bro "Engines of Creation" (1986) adelantó las promesas y peligros de la manipulación molecular. Charles Vest fue un gran impulsor de los descubrimientos de nanomateriales y en 2001 predijo que la nanotecnología nos llevará a una segunda revolución industrial en el siglo XXI, pues supondrá la disponibilidad de nuevos materiales con propiedades extraordinarias (más fuertes que el acero pero con solamente el diez por ciento de su peso), nuevas aplicaciones informáticas con componentes increíblemente más rápidos, así como sensores moleculares capaces de detectar y destruir células cancerígenas en las partes más delicadas del organismo.

En 1985 la investigación interdisciplinar permitió el advenimiento del buckyball y en 1991 aparecen los nanotubes de carbono. En 1996 Sir Harry Kroto gana el Premio Nobel por haber descubierto los fullerenes. A partir de 2000, organizaciones de protección del medio ambiente comienzan a difundir sus temores acerca del peligro ecológico y las consecuencias de la nanotecnología sobre la salud, reclamando un mayor control de las investigaciones sobre el tema.

Se admite que la más cuantiosa financiación para la investigación de nanopartículas fue instaurada por el presidente Clinton, a iniciativa de Drexler. A este último se le atribuye la creación del término nanotecnología, aunque algunas revisiones dan cuenta que el vocablo ya había sido utilizado por Taniguchi en Japón. Otro investigador de esta disciplina fue Richard Smalley, de opiniones opuestas a Drexler en lo referente a los peligros de la manipulación de nanopartículas (autorreplicación fuera de control), siendo célebre el debate mantenido por ambos en 2003.

\section{NANOMATERIALES}

Naturaleza. Con la denominación "nanomateriales" se conocen las estructuras creadas por la investigación nanotecnológica, cuyo tamaño oscila entre 1 y $100 \mathrm{~nm}{ }^{11}$. A tal escala, la materia adopta propiedades muy diferentes de las que exhibe a gran escala: los nanomateriales serán más fuertes, más ligeros, mejores 
conductores de la electricidad, más porosos, menos corrosivos. Aún siendo de naturaleza inorgánica, los nanomateriales acumulan un potencial extraordinario para resolver desafíos como detectar cambios eléctricos en moléculas biológicas, los cuales se canalizan hacia el descubrimiento y/o tratamiento de una enfermedad.

En general, la nanotecnología puede ser vista como una serie de "herramientas, dispositivos y materiales inteligentes o máquinas" que aunados a otros instrumentos (microscopio de fuerza atómica, microscopio de exploración por tunelización, softwares de modelización molecular) permiten la visualización y/o manipulación de nanoelementos como células, bacterias, virus y moléculas. Los nanofármacos podrían acarrear genes $\mathrm{y}$ agentes antivirales y antibacterianos hasta el interior de las células, tornando más eficaces los tratamientos de las enfermedades. Las nanopartículas (1-100 nm) aventajan a las micropartículas (actualmente en uso) por ofrecer mayor superficie para el mismo volumen, atravesar poros más pequeños y ser más solubles (biodifusibles). Además, ciertas nanoestructuras pueden ser dirigidas para que atraigan células o microorganismos, o bien se unan específicamente con determinados compuestos o moléculas y liberen su carga útil. Los principales nanomateriales son:

Fullerene (fullereno): molécula compuesta al menos por 60 átomos de carbono, que adopta la forma de balón (Figura 2) o cúpula geodésica (“buckyball”). Fullerenos y nanotubos pueden ser 100 veces más fuertes que el acero, más conductivos que el cobre y más seguros para determinadas aplicaciones médicas. Por ser huecos, pueden "rellenarse" con quimioterápicos o agentes radiactivos que operarán en sitios cuidadosamente delimitados. Vacunas a base de antígenos vehiculizados en nanoesferas biodegradables lograrían mejores resultados que las producidas por métodos convencionales.

Nanotube (nanotubo): estructura cilíndrica y delgada integrada por una secuencia de 60 átomos de carbono en una sola fila (Figura 3), relacionada con otras formas cristalinas del carbono, tales como grafitos y diamantes. Semeja una "tela metálica" pero por ser miembro de la familia de los fullerenos su origen puede derivar de la expansión de un buckyball (buckytube) de tamaño no mayor de $1 \mathrm{~nm}$. Los nanotubos con propiedades antibacterianas están formados por auto-ensamblado de péptidos cíclicos. Son capaces de insertarse en las membranas celulares bacterianas y destruirlas, tanto in vitro como in vivo.

Dendrimer (dendrímero): macromoléculas tridimensionales sintetizadas a escala nanométrica, que se construyen añadiendo monómeros hasta formar un polímero de apariencia arbórea (Figura 4). Los dendrí-

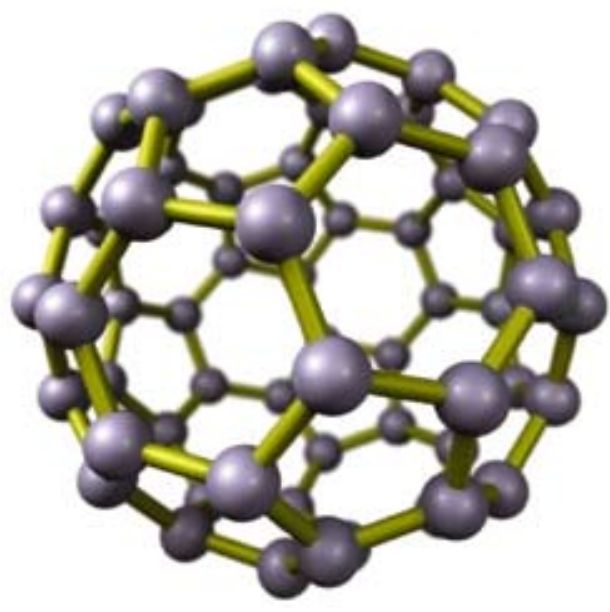

Figura 2. Fullereno.

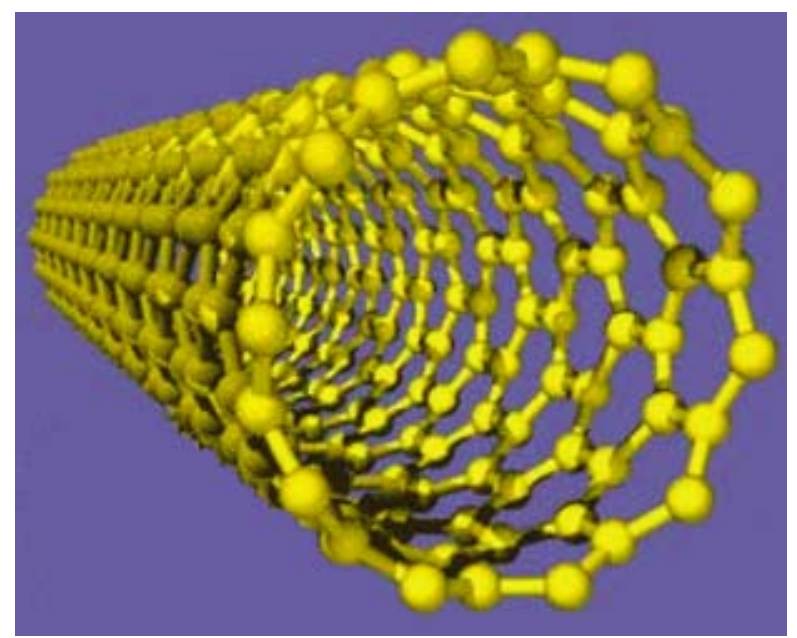

Figura 3. Nanotubo.

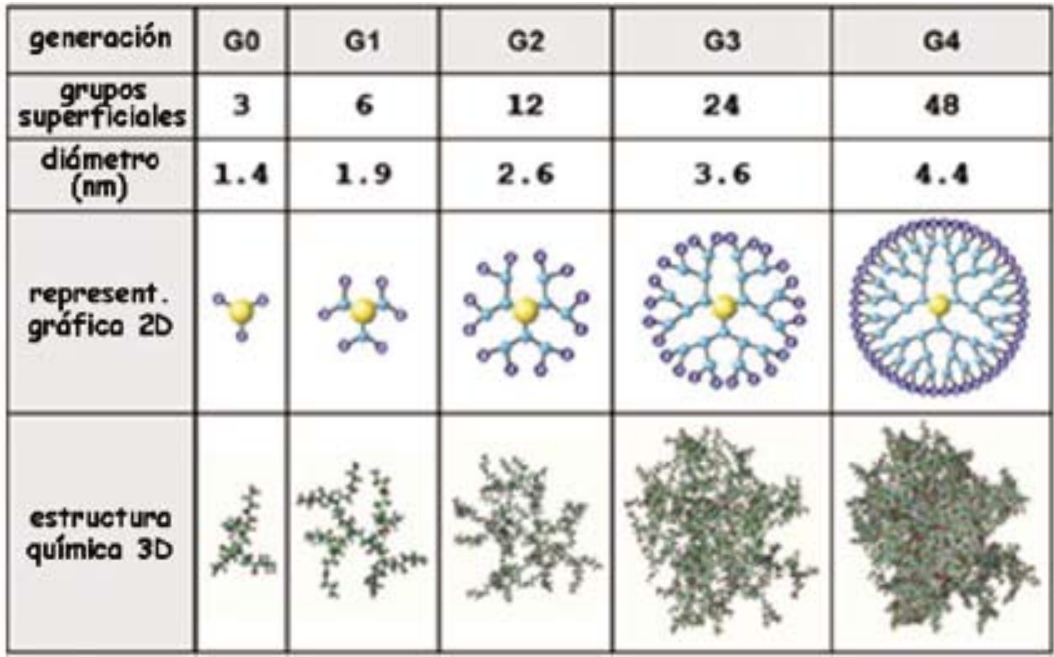

Figura 4. Evolución de un dendrímero.

meros son capaces de contener (almacenar) moléculas de fármacos en su interior y operar como vehículo de reparto; pueden penetrar fácilmente a las células y liberar drogas directamente en el blanco (target), además de desencadenar respuestas del sistema inmunológico. Ello sería singularmente útil en el tratamiento de los tumores malignos. Los dendrímeros de cuarta gene- 
ración han demostrado resultados prometedores como herramientas de resonancia magnética de imágenes y técnicas de transferencia génica.

Quantum dots (puntos cuánticos): esferoides de cristales de seleniuro de cadmio a nivel de nano-escala (Figura 5), los cuales son capaces de absorber la luz blanca y a continuación (nanosegundos más tarde) re-emitirla en un color específico, por lo cual resultan potencialmente útiles para el diagnóstico, los análisis genéticos y la investigación farmacológica. En reemplazo de la marcación por colorantes fluorescentes, los puntos cuánticos ofrecen la ventaja que variando el tamaño del cristal puede lograrse un arco iris de colores para fluorescencia, que permanecen "encendidos" durante mucho más tiempo que los colorantes, de utilidad para la detección de proteínas y genes con sondas moleculares (secuencias de ADN o proteínas) iluminadas con rayos ultravioletas. Puntos cuánticos inyectados al organismo podrían detectar células cancerosas, introducirse dentro de ellas y responder al estímulo de un flash generando el calor suficiente para destruirlas.

Nanoshell (nanoenvoltura): en palabras sencillas, es una caparazón de oro encerrando un nanocristal esférico (Figura 6). Por definición, son esferas concéntricas de $100 \mathrm{~nm}$ de diámetro compuestas por un núcleo dieléctrico o core (sílice o sulfuro de oro) y un recubrimiento metálico (oro), de manera que combinen la actividad óptica infrarroja con la propiedad coloidal biocompatible del oro (el cual no estimula el sistema inmune). Al variar el espesor de la envoltura metálica, se puede sintonizar con precisión el color de la luz a la que responderá el nanoshell. Este nanomaterial ha demostrado gran utilidad para mejorar las técnicas de inmunoensayos realizados en sangre, p.ej. detectar IgG en cantidad menor a una milmillonésima parte de un gramo por mililitro de sangre. Cuando los anticuerpos (nanoshells) se unen a la molécula investigada, se generan ligeros cambios en las propiedades ópticas de la nanoenvoltura, que pueden ser monitoreados para detectar específicamente pequeñísimas cantidades de la molécula investigada. Inyectados a un animal presuntamente canceroso, los nanoshells podrían indicar el sitio y la magnitud de la neoplasia al ser expuestos por un láser de luz infrarroja. Se asevera que además de acumularse en las células malignas, los nanoshells producirían su destrucción al concentrar la luz y producir calor.

Nanodrops (nanogotas): el aceite de soja en su forma normal tiene muy pocas o ninguna aplicación médica, pero una vez emulsionado con detergentes para formar gotitas de diámetro inferior a $600 \mathrm{~nm}$ (nanodrops), opera como un potente destructor de bacterias $\mathrm{y}$ virus debido a fenómenos de tensión superficial que no afectan las estructuras celulares de organismos superiores, por lo cual pueden utilizarse externamente en seres humanos y animales.

Nanocables: se han desarrollado nanocables coaxiales utilizando nanotubos peptídicos autoensamblables como plantilla. El péptido base fue la difenilalanina; los nanotubos fueron recubiertos con oro y sus

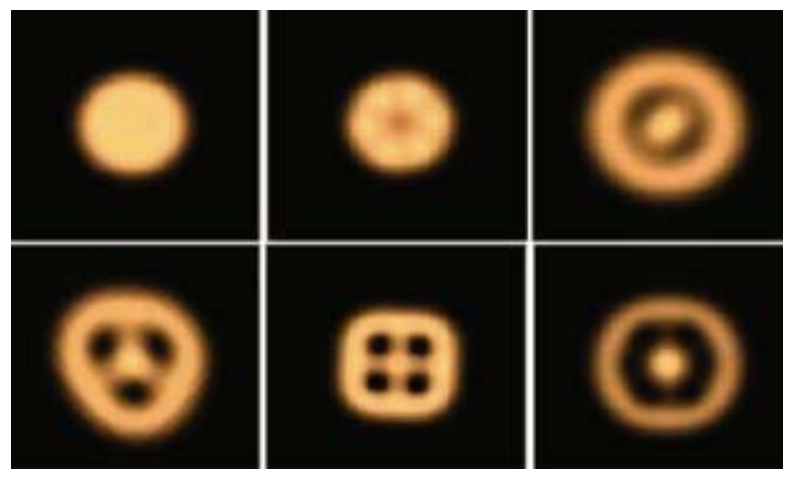

Figura 5. Puntos cuánticos.

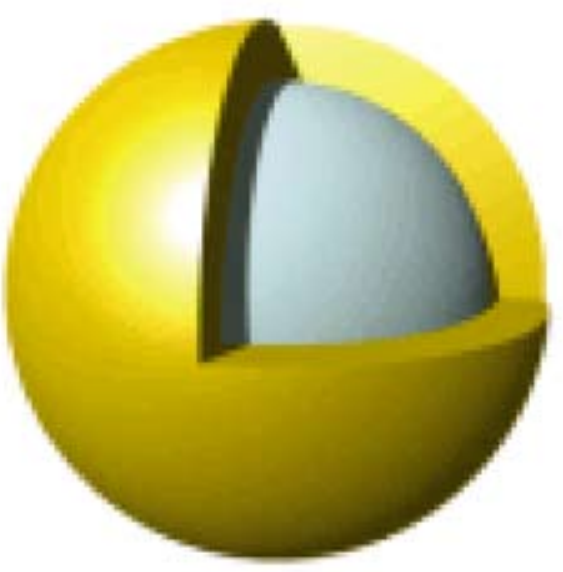

Figura 6. Nanoshell.

núcleos rellenados con plata. Los péptidos permitieron unir nanopartículas de oro de 1,4 nm de diámetro a la superficie de los nanotubos. Las nanopartículas de oro actuaron como sitios de nucleación para la deposición de iones metálicos sin corriente eléctrica. De este modo, se logró un recubrimiento de oro alrededor del nanotubo de unos 20 nanómetros de grosor. La estructura resultante (metal-aislante-metal) ofrece ventajas para disipar interferencias electromagnéticas ${ }^{13}$.

Nanobots (nanorobots): se está investigando la posibilidad de crear nanomáquinas que puedan ser inyectadas en el cuerpo para controlar infecciones o reparar células. Probablemente deban transcurrir varias décadas hasta que esta nanotécnica esté comercialmente disponible.

\section{APLICACIONES}

Aplicaciones en medicina veterinaria. La nanotecnología es uno de los más conspicuos actores de la revolución científica que marca el principio del nuevo milenio. El descubrimiento de inesperados comportamientos físicoquímicos de la materia a escala nanométrica ha abierto el camino de nuevas tecnologías útiles para la medicina veterinaria, especialmente los nanofármacos (medicamentos basados en la química específica de las nanopartículas) y los nanodispensadores (transportadores con destinos específicos programados) ${ }^{24}$. 
Recientemente se han creado nanopartículas que imitan la superficie de la membrana celular de los enterocitos del pollo. Arribadas al intestino por vía oral, cuando algún germen se acerca a las partículas, éstas se cierran envolviendo al microorganismo, tras lo cual se aglutinan unas con otras y se eliminan a través de las deyecciones. Tales nanopartículas constituyen un "alimento inteligente" capaz de proteger al ave de algunas enfermedades infecciosas ${ }^{6}$.

Remplazando la vacuna tradicional contra el virus de la aftosa, péptidos conjugados con nanopartículas inertes provocaron significativas respuestas inmunes celulares y humorales en ovejas ${ }^{14}$. La nanotecnología constituye hoy una herramienta alternativa para luchar contra el arbovirus de la "lengua azul" de los animales domésticos, dada la posibilidad de obtener una vacuna efectiva contra la enfermedad ${ }^{3}$.

La nanotecnología posibilitó la existencia de una nueva ruta de vehiculización de fármacos. En modelos animales, nanopartículas pudieron ser transportadas directamente desde la nariz al cerebro a través del epitelio olfativo y los nervios trigéminos, con la ventaja de no ser afectadas por reflujo mucoso ni degradación en la cavidad nasal ${ }^{22}$.

Se estima que una de las principales contribuciones de los dendrímeros será el diagnóstico y la erradicación de los tumores malignos que afectan a la población geriátrica de pequeños animales, al liberar quimioterápicos e isótopos radiactivos dentro de la microvasculatura del tumor. El mismo principio podría aplicarse al hipertiroidismo del gato ${ }^{11}$.

Desde la perspectiva del tratamiento, se han utilizado nanopartículas para introducir fármacos y genes en las células afectadas por una enfermedad o bien para identificar y destruir determinadas células diana, por ejemplo, tumorales. En este último caso, se han empleado nanocristales cuánticos que al ser excitados re-emiten luz fluorescente en una longitud de onda determinada que depende directamente del tamaño del cristal. Inyectados en el torrente circulatorio del animal pueden poner en evidencia células dañadas mediante la iluminación específica. Se han diseñado nanotubos que al ser inyectados en la sangre se concentran en torno a un tumor. Si se expone el animal a la luz infrarroja, los nanotubos absorben rápidamente esta energía y se calientan hasta $55^{\circ} \mathrm{C}$, destruyendo el tumor sin dañar los tejidos circundantes (Figura 7) ${ }^{8,20}$

En Argentina, el INTI está desarrollando nanoadyuvantes mucoadhesivos para uso veterinario, así como para implantes dentales y prótesis endóseas y articulares. En colaboración con el INTA se están estudiando las vías oral e intranasal para la administración de antígenos microencapsulados y su liberación controlada, para la prevención de enfermedades de porcinos y bovinos, entre ellas la queratoconjuntivitis bovina. Se diseñaron nanomatrices de quitosano, una especie de "nanonave transmucosa" que además de ser mucoadhesiva será plausible de ser capturada por células del sistema inmune. Para proteger el antígeno y posibilitar

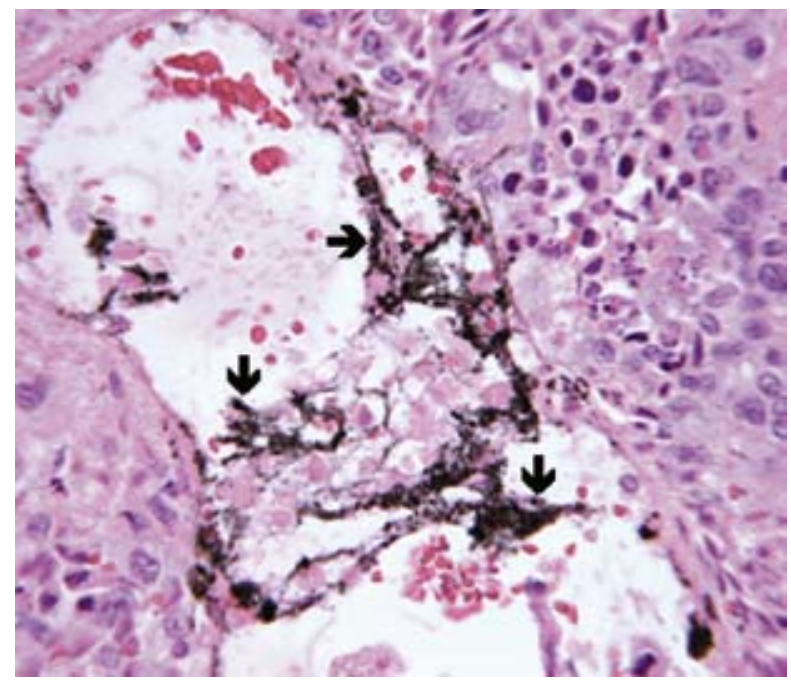

Figura 7. Células cancerosas del hígado del conejo están siendo destruidas por el calor generado por nanotubos de carbono (flechas) inyectados y luego activados por ondas radiofónicas ${ }^{8}(400 x)$.

su entrada a través de las placas de Peyer se dispondrá de arqueosomas, vesículas para delivery preparadas a partir de lípidos (arqueolípidos: éteres del glicerol con cadenas poli-isoprenoides), de elevada resistencia estructural en entornos fisicoquímicos hostiles, capaces de degradar otras vacunas ${ }^{15}$.

Las nanopartículas han revelado utilidad para el diagnóstico de enfermedades, así como para actuar como sistemas de transporte y entrega de medicamentos. La investigación ha demostrado la viabilidad de introducir nanotubes y nanoshells en los animales para buscar y destruir determinadas células blanco. Mientras es razonable presumir que en un futuro cercano los desarrollos de la industria nanobiotecnológica revolucionarán la medicina veterinaria, existe también una gran preocupación sobre su repercusión en las áreas de la alimentación y la salud, así como problemas sociales y éticos que pueden demorar o desviar los avances tecnológicos ${ }^{29}$.

Las ADN-nanomáquinas (DNA-nanomachines) son ensambles sintéticos cuya estructura molecular cambia al ser estimulada por gatillos externos, como fue demostrado en animales. Uno de estos dispositivos es capaz de ser activado por protones y funcionar in vivo como un sensor de $\mathrm{pH}$ al transferir energía desde el interior de una célula por resonancia fluorescente, informando (con un rango de 5,5 a 6,8) el estado del $\mathrm{pH}$ intracelular ${ }^{23}$.

En la actualidad si un animal resulta afectado por una enfermedad, pueden pasar días e incluso semanas o meses antes de que los síntomas se hagan evidentes. A esas alturas la infección puede haberse extendido lo suficiente como para hacerse incontrolable y acabar con la vida de numerosos ejemplares. La nanotecnología opera mediante la detección y erradicación tempranas. Por ejemplo, un sistema de tratamiento inteligente podría consistir en un dispositivo en miniatura implantado en el animal, que muestree (analice) regularmente 
su saliva. Mucho antes de que aparezcan los síntomas, el sistema integrado de detección y control alertaría sobre la presencia de la enfermedad y notificaría al productor o al veterinario para instaurar el tratamiento adecuado ${ }^{20}$.

Las filomicelas son nanopartículas con forma de filamento que pueden circular en la sangre aproximadamente 10 veces más tiempo que sus contrapartes esféricas. Esta propiedad está siendo investigada para mejorar el diseño de sistemas para la entrega de drogas en tratamientos contra el cáncer. De hecho, resultados preliminares muestran que las filomicelas pueden efectivamente entregar el anticancerígeno paclitaxel y reducir tumores malignos en ratones ${ }^{7}$.

Puntos cuánticos de Mn emisores de infrarrojo, guiados hasta receptores de células cancerosas del páncreas de ratones, se utilizaron exitosamente para obtener imágenes de alto contraste, sin registrarse efectos tóxicos a largo plazo ${ }^{31}$.

El desarrollo de "dosificadores inteligentes" a escala nanométrica plantea la posibilidad de diseñar dispositivos que contengan diminutas dosis de fármacos u hormonas convenientemente empaquetadas, que no liberarían su contenido hasta no alcanzar las células diana en el animal. Tales dosificadores funcionarían según los mismos principios que regulan la inyección de combustible en los modernos motores de explosión, los cuales mediante sensores ajustan de manera precisa y continua el aporte. La identificación de las células diana se llevaría a cabo mediante "etiquetas moleculares", es decir identificaciones químicas de tejidos concretos. Esta sofisticada estrategia implicaría tratamientos de mayor precisión y reducción de la cantidad de fármacos a emplear, ítem este último de significativa importancia en medicina veterinaria ${ }^{20}$.

Debido a las limitaciones y los costos de la experimentación con animales, se están llevando a cabo investigaciones para encontrar alternativas viables y efectivas. El campo de la nanotecnología permite reducir los experimentos con animales mientras se mantiene la seguridad para los pacientes y los consumidores. Se está trabajando en sistema de biorreactores a nanoescala para detecciones toxicológicas, con el fin de mejorar la sensibilidad de las pruebas in-vitro ${ }^{10}$.

La última década ha provocado impresionantes adelantos en la ciencia e ingeniería de los materiales, como el uso de componentes microelectrónicos, que se tradujeron en mejorías de las técnicas de diagnóstico y control de las enfermedades animales. Estas herramientas sostienen la promesa de miniaturizar dispositivos de diagnóstico que podrían reducir los costos y aumentar la sensibilidad de una amplia gama de pruebas de diagnóstico veterinario. Los recientes desarrollos, como la nanotecnología, han llevado a la proliferación de novedosas y rápidas pruebas diagnósticas ${ }^{4}$.

Una interesante aplicación de la nanotecnología a la producción animal es el empleo de nanosensores biodegradables para el ganado. Estos podrán ser implantados en los animales y permitirán su localización constante, así como monitorear el estado de salud enviando la información a un computador central. Otros nanosensores podrían ser utilizados en el control de la trazabilidad de productos animales, ya que permitirían la detección de cantidades muy pequeñas de contaminantes, virus o bacterias en la cadena alimentaria. Por ejemplo, podrían usarse en pollos para eliminar la bacteria Campylobacter $s p$., que no produce síntomas en las aves pero sí en los seres humanos que ingieren su carne ${ }^{20}$.

En São Paulo, trabajos coordinados entre EMBRAPA y trece universidades brasileras están investigando aplicaciones agropecuarias de la nanotecnología. A nivel de medicina veterinaria se está desarrollando un sistema de diagnóstico de enfermedades animales basado en la nanociencia, así como nanopartículas capaces de liberar in vivo drogas terapéuticas en forma controlada. A nivel de producción de alimentos puede mencionarse el descubrimiento de una solución que contiene nanopartículas con enzimas retardantes de la descomposición de las frutas, que al ser asperjadas aumentan hasta 12 meses su perdurabilidad post-cosecha (Figura 8). Una "lengua electrónica" permite clasificar vinos y cafés por su sabor, merced a sensores de nanopartículas que operan de manera similar al sistema gustativo humano. Una "nariz electrónica" permitiría establecer el grado de maduración de las frutas, especialmente bananas. Nanopartículas agregadas a fibras de coco y almidón de maíz posibilitaron la síntesis de un plástico biodegradable. También se están ensayando diversos fertilizantes inocuos para productores y medio ambiente, así como nanopartículas que aceleran la degradación y eliminación de residuos tóxicos ${ }^{27}$.

Aplicaciones en producción agropecuaria. La nanotecnología posee un potencial capaz de revolucionar la producción agropecuaria. Los ejemplos de aplicaciones en producción animal incluyen el uso de nuevas herramientas moleculares y celulares para la reproducción animal, preservación de la identidad del animal desde el nacimiento hasta la mesa del consumidor ("trazabilidad"), bioseguridad de los alimentos de origen animal, mejor comprensión de los fenómenos que rigen la nutrición animal desde la ingestión de la dieta hasta la captación y utilización del nutriente y otras ${ }^{29}$.
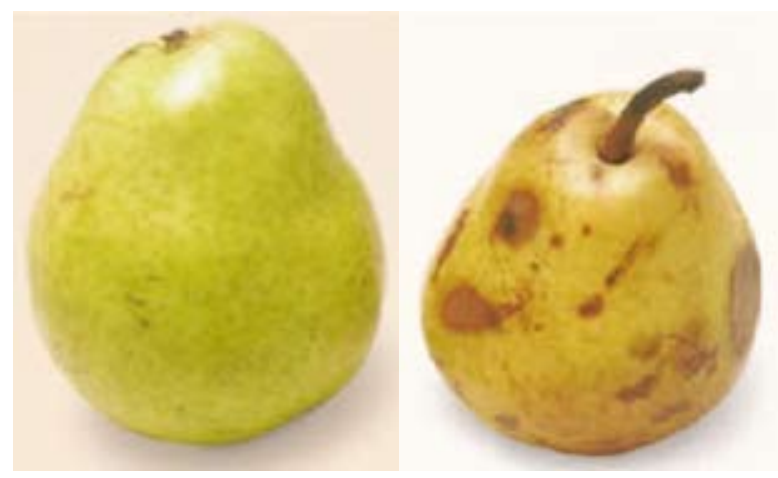

Figura 8. Frutas luego de 30 días de ser cosechadas. Izquierda: tratada con nanopartículas. Derecha: sin tratamiento. 
El campo podría utilizar insumos a nanoescala para optimizar tanto la agricultura (mejora de la producción, agricultura de precisión, plaguicidas, herbicidas, invernaderos, reducción del empleo de agua, suelo, fertilizantes y fitosanitarios, detección de niveles de agua, nitrógeno, plagas, polen y agroquímicos), como la ganadería (nanochips para la identificación animal, nanopartículas para la administración de fármacos o vacunas, detección de enfermedades mediante nanosistemas, tratamientos) ${ }^{9}$. Se están ensayando técnicas que aumenten la apetencia del ganado hacia determinadas pasturas impregnadas con nanopartículas ${ }^{20}$.

La nanotecnología avanza inexorablemente y la industria registra gran cantidad de aplicaciones de partículas menores de $100 \mathrm{~nm}$ vigentes en procesos industriales, entre ellos la producción de alimentos. Es urgente la necesidad de evaluar los riesgos de las nanopartículas. Investigando 197 compañías suizas, 43 declararon usar o producir nanopartículas y 11 importaron y comercializaron productos que las contenían (especialmente derivados de Ag, Al, Fe, Si, Ti, Zn). Las industrias de alimentos, cosméticos y pinturas fueron las que emplearon las mayores cantidades de nanopartículas ${ }^{28}$.

En el rubro conservación de alimentos se han ensayado nanotécnicas para aumentar la flexibilidad mecánica, el efecto bactericida y la estabilidad térmica de la cáscara del huevo de gallina ${ }^{18}$. Las nanotécnicas serían útiles para la producción agrícola, especialmente para el procesamiento de alimentos transgénicos ${ }^{8}$ . En el área de la producción animal el INTI está investigando la aplicación de identificadores inteligentes de radiofrecuencia para la trazabilidad del ganado y la detección activa de vacunación ${ }^{15}$.

Se han desarrollado experimentalmente nanotubos que implantados bajo la piel de vacas lecheras operan como sensores en tiempo real de los niveles de hormonas gonadales (estradiol), revelando con precisión el estado del ciclo reproductivo del animal, ya que los nanotubos se unen al anticuerpo del estradiol en el momento del estro y lo revelan por fluorescencia infrarroja ${ }^{20}$.

En la industria alimentaria las nanotécnicas están en fase de "despegue", investigándose su impacto en el fortalecimiento de la calidad y seguridad de los alimentos a través de biosensores: nanochips, microarrays, nariz y lengua electrónicas; análisis de composición, estimación de la vida útil y frescura, detección y neutralización de microorganismos alterantes y patógenos, aditivos, fármacos, toxinas, metales pesados, plaguicidas, fertilizantes, contaminantes abióticos; detección de factores antinutricionales y alérgenos. También tienen ingerencia sobre el control de procesos (biosensores: nariz y lengua electrónicas), envases activos, nanoenvases, nanoetiquetado miniaturizado, desarrollo de nuevos alimentos (nanoalimentos y "gastronomía molecular"), alimentos interactivos, alimentos funcionales, alimentos más saludables, nutritivos y/o con mejores características organolépticas y reológicas, mejora de la productividad y reducción de $\operatorname{costos}{ }^{9}$.
Científicos del Agricultural Research Service (USA) han desarrollado un sensor biológico microscópico que detecta Salmonella sp. en alimentos. Los biosensores incluyen partículas de tinta orgánica fluorescente unidas a anticuerpos anti-bacteria. Los anticuerpos se adhieren al microorganismo provocando que la tinta brille, facilitando la detección de las bacterias. El sensor se adaptó para detectar otros gérmenes patógenos presentes en alimentos y puede ofrecer grandes posibilidades a la bromatología ${ }^{25}$.

El campo de la nanotecnología abre nuevas aplicaciones para la producción de alimentos, como la protección de las cosechas. Herbicidas sistémicos vehiculizados en nanocápsulas evitarían los frecuentes fenómenos de fitotoxicidad. Además, las nanocápsulas mejorarían la aplicación del herbicida, aumentando su penetración a través de las cutículas y permitiendo la constante y lenta descarga de sus principios activos ${ }^{26}$.

Aplicaciones en medicina humana. En el Departamento de Nanotecnología de la Comisión Nacional de Energía Atómica (Argentina), investigadores del CONICET están construyendo un biosensor capaz de detectar precozmente la existencia de enfermedades como cáncer, Chagas y SIDA a partir de muestras de sangre o saliva. El diagnóstico de estas afecciones en etapas iniciales posibilitaría tratamientos más efectivos. El dispositivo contendrá cientos de sensores compuestos por nanocables de $300 \mathrm{~nm}$ de longitud a los que estarán adosados anticuerpos para reconocer específicamente a los antígenos característicos de ciertas enfermedades virales, bacterianas o neoplásicas. Cuando el sensor reconozca una molécula relacionada con la enfermedad a detectar, producirá una señal eléctrica que al ser interpretada por un software se traducirá en un diagnóstico claro y específico, que podrá ser leído en la pantalla de una computadora ${ }^{19}$.

La nanociencia participa del mejoramiento de la medicina y la farmacia a través de técnicas de diagnóstico, detección y análisis basados en nanochips, nanosistemas para la administración localizada y gradual de fármacos o vacunas, nanotubos de carbono y otros dispositivos para luchar contra el cáncer, diseño y desarrollo de nuevos fármacos, eliminación de microorganismos patógenos, desarrollo de células artificiales, mejora en la compatibilidad de implantes, desarrollo de nanomateriales para la ingeniería tisular y la terapia génica y celular, instrumental de mayor precisión y -entre otros- corrección de déficits auditivos y visuales ${ }^{9}$.

Nanotubos de carbono han sido utilizados para "contrabandear" moléculas que bloquean el VIH dentro de células humanas. Aunque es un resultado preliminar, el descubrimiento podría conducir a nuevos tratamientos contra el virus ${ }^{7}$. Un carrier de ácidos nucleicos, el nanogel polyethylene glycol-polyethylenimine 6(hydroxymethyl)-1,4-anthracenedione (PEG-PEI), demostró ser capaz de transportar una pequeña molécula anticancerígena ${ }^{12}$. 
Ciertos fullerenos fueron capaces no solamente de destruir amiloide maduro sino también de impedir in vivo la formación de nueva sustancia amiloide, por lo cual son considerados potenciales herramientas en la terapia de la amiloidosis ${ }^{21}$.

Los dendrímeros están siendo utilizados para superar las barreras biológicas y optimizar las aplicaciones biomédicas in vivo. Recientemente se ensayó con éxito un dendrímero biodegradable con core infrarrojo y envoltura de polietileno, que reveló suficiente lapso de permanencia en sangre para posibilitar pruebas de fluorescencia ${ }^{1}$.

La biocompatibilidad y el uso como sistema drug- $^{-}$ delivery de nanopartículas magnéticas y magnetoliposomas, así como su utilidad como marcadores de resonancia magnética en el diagnóstico del cáncer, están siendo estudiados por el INTI. Una de las enfermedades a ser tratadas con liposomas será la leishmaniasis cutánea. También se investiga la obtención y mejora de biomateriales y productos biomédicos, aleaciones de $\mathrm{Ni}$-Ti para su uso en prótesis endóseas y articulares, fijaciones de fracturas óseas, corrección de defectos de columna, materiales para stents, válvulas cardiovasculares e instrumental quirúrgico para cirugías no invasivas. Para uso odontológico se están ensayando las características de curado, propiedades mecánicas y dureza de nanocompuestos, así como nuevos materiales para endodoncia y ortodoncia ${ }^{15}$.

Otras aplicaciones. Se ha inventado un nuevo y altamente eficiente dispositivo a nanoescala que contiene miles de ultradelgados espejos por milímetro cuadrado para mejorar los telescopios espaciales de rayos X. El concepto también podría abrir nuevas vías para dispositivos de óptica de neutrones y para la difracción de electrones, átomos y moléculas. Ya existen fibras sintéticas fabricadas con nanotubos de carbono, material varias veces más fuerte, duro y rígido que las fibras actualmente utilizadas. La nanociencia también provee materiales para electrónica, energía (nuevos materiales fotovoltaicos, baterías), catálisis, láseres en reproductores de CD, espejos y lentes de alta calidad ${ }^{8}$.

El mejor sistema actual de registro informático de datos basado en la memoria magnética, puede guardar alrededor de 2 gigabits $/ \mathrm{cm}^{2}$; los científicos creen que el límite físico de la capacidad de este sistema (no alcanzado aún) es de alrededor de 25 gigabits $/ \mathrm{cm}^{2}$. Un sistema nanométrico de miniaturización de registros de datos (matriz de más de mil agujas que inscriben bits de $50 \mathrm{~nm}$ de diámetro) logró guardar 35 gigabits/ $\mathrm{cm}^{2}$ (hasta 80 gigabits $/ \mathrm{cm}^{2}$ si se utiliza una aguja única) y es capaz de hacerlo a la velocidad de los artefactos magnéticos actuales. Con unidades de almacenamiento provistas de matrices gigantescas, con millones de agujas, se podría lograr almacenamientos del orden de los terabytes, algo así como 40 veces lo que hoy está disponible ${ }^{30}$.

Otros adelantos relacionados a la nanotecnología son la computadora de ADN, un nuevo tipo de papel (partículas submicroscópicas de celulosa) que resulta tan resistente a las roturas como el hierro fundido, ropa resistente a la contaminación por tóxicos químicos, alérgenos, microorganismos (uso hospitalario) o indumentaria capaz de cambiar de color para crear camuflaje (uso militar), así como fibras de nylon o lana (con nanopartículas cargadas electrostáticamente) que respondan al ambiente de manera automática, de forma que las personas que utilicen prendas fabricadas con ellas no sufran cambios en su temperatura corporal y controlen la sudoración ${ }^{8}$.

Los tejidos inteligentes resultan muy útiles para veterinarios, médicos, soldados y otros profesionales, al posibilitar la confección de ropa que se adapte a condiciones cambiantes y proporcionar niveles regulables de protección ante microbios, agentes químicos y radiación. Los fabricantes ven un gran potencial en la ropa que brilla, no se arruga o evita el olor corporal. Ya se pueden fabricar materiales que hagan algunas de estas cosas, pero todavía son muy voluminosos, rígidos o complicados para su uso práctico, por lo que el objetivo es fabricar un material ligero y fácil de tejer pero que también sea muy duradero y, con el fin de transmitir información, que sea capaz de conducir la electricidad. Se ha desarrollado un método con el que ello podría lograrse, recubriendo hilos de algodón con nanotubos de carbono ${ }^{16}$.

Riesgos de la nanotecnología. Los peligros por "sustancias viscosas" son hoy menos probables que cuando las imaginó Drexler, una máquina nanométrica que se autorreplica y consume todas las partículas orgánicas vivas o muertas, creando un cieno, una viscosa masa orgánica muerta. Hoy se piensa que este fenómeno estaría limitado por el mismo mecanismo que restringe todas las formas vivas: la energía disponible. Los críticos de la nanotecnología puntualizan que a corto plazo habrá fenómenos de toxicidad atribuibles a las nuevas clases de nanosustancias que podrían afectar de forma adversa a la estabilidad de las membranas celulares o distorsionar el sistema inmunológico cuando son inhaladas o ingeridas. Hay una posibilidad que las nanopartículas en agua potable pudieran ser dañinas para seres humanos y animales. Las células del colon expuestas a partículas de dióxido de titanio mueren a mayor velocidad de la normal ${ }^{30}$.

La Royal Commission on Environmental Pollution (UK) ha admitido la necesidad de una acción reguladora urgente de los materiales a nanoescala cuyo uso está ampliamente extendido en la industria británica. Por el momento, no hay pruebas de que estos materiales sean dañinos para las personas o el medio ambiente, pero existe un importante vacío en cuanto a investigación de los riesgos planteados por estos materiales, presentes globalmente en unos 600 productos, como ropa con nanopartículas de plata. Preocupa que las nanopartículas de plata lleguen al medio ambiente porque podrían ser potencialmente muy perjudiciales ${ }^{17}$. 
Científicos del área de conservación de alimentos han reconocido las grandes ventajes que introduciría la nanotecnología a dicha disciplina, aunque también enfatizan la necesidad de investigar cuidadosamente los efectos de las nanopartículas sobre el alimento humano $\mathrm{y}$ animal para evitar el riesgo de los consumidores ${ }^{5}$.

La "militarización" de la nanotecnología es una aplicación potencial. La electrónica molecular podría ser usada para construir sistemas informáticos útiles para misiles. Los nanomateriales avanzados tienen aplicaciones para mejorar las armas existentes y el hardware bélico a través de nuevas propiedades (tales como modificaciones de la relación fuerza-peso o de la reflexión de la radiación electromagnética para aplicaciones sigilosas). No obstante, no hay ninguna manera obvia de que alguna de las formas que se tienen en la actualidad o en un futuro próximo puedan ser militarizadas más allá de lo que lo hacen otras tecnologías como la ingeniería genética. La nanotecnología puede ser usada para crear dispositivos no detectables (como micrófonos o cámaras de tamaño de una molécula). Son posibilidades que entran en el terreno de lo factible. El impacto social de tales dispositivos dependería de muchos factores, incluyendo quién ha tenido acceso a él, cuan eficientes son y cómo son usados ${ }^{30}$.

Si bien es capaz de revolucionar el cuidado de la salud al brindar poderosas herramientas para diagnosticar y tratar las enfermedades desde un nivel molecular, algunos opinan que la nanomedicina podría desviar los escasos fondos destinados a investigación y desarrollo de la medicina convencional y a los servicios esenciales de salud, disminuyendo los recursos directos destinados a los aspectos no médicos de la salud y el bienestar comunitarios. Aunque se proclama que la medicina nanológica es una solución a las urgentes necesidades de salud en el sur del globo, en realidad surge del norte y está diseñada primordialmente para los mercados ricos ${ }^{8}$.

\section{CONCLUSIÓN}

Las extraordinarias implicaciones científicas, tecnológicas, industriales, socioeconómicas, energéticas,

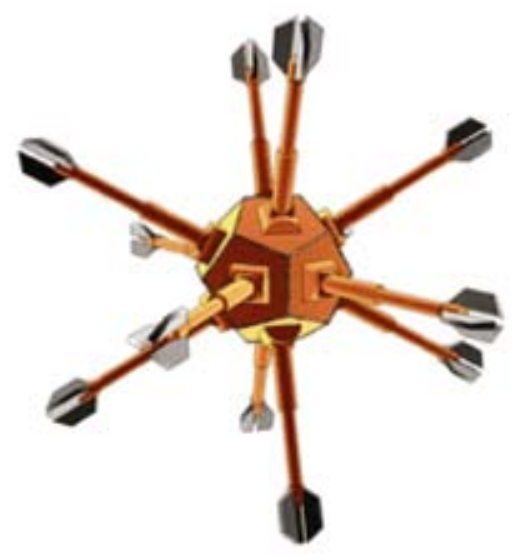

Figura 9. Nanorobot (idealización). medioambientales, agroalimentarias y sanitarias de la nanotecnología son prácticamente infinitas y sólo están limitadas a mediano y largo plazo por la imaginación y capacidad creativa de los científicos.

Pensar en una máquina submicroscópica que inyectada al organismo opere reparando determinadas estructuras dañadas (Figura 9) ¿es propia de la ficción y escapa de la posibilidad científica? Quienes (como el autor de este artículo) solían deleitarse con la lectura de libros clásicos, no dejarán de advertir que en aquellos años juveniles nos hicimos la misma pregunta al leer "De la tierra a la luna" (Julio Verne, 1865).

Como para cualquier otra tecnología, la bondad o maldad de la nanotecnología dependerá de las aplicaciones y fines a los que se destine. Aún estamos a tiempo de encauzar esta incipiente revolución científica hacia caminos racionales y constructivos, sin perder de vista la relación riesgo-beneficio y fijando como meta la mejoría de la calidad de vida de las comunidades, tanto actuales como venideras.

\section{REFERENCIAS}

1. Almutairi A, Akers WJ, Berezin MY, Achilefu S, Fréchet JM. 2008. Monitoring the biodegradation of dendritic near-infrared nanoprobes by in vivo fluorescence imaging. Mol Pharm 5: 1103-1110.

2. Anónimo. 2009. Los productos desarrollados con nanotecnología representarán el $15 \%$ de los manufacturados en la próxima década. Noticias EuropaPress 17: 01. On line: www.hoytecnologia.com/noticias/productos-desarrollados-nanotecnologia-repr esentaran/100807.

3. Bhanuprakash V, Indrani BK, Hosamani M, Balamurugan V, Singh RK. 2009. Bluetongue vaccines: the past, present and future. Expert Rev Vaccines 8: 191-204.

4. Bollo E. 2007. Nanotechnologies applied to veterinary diagnostics. Vet Res Commun Suppl 1: 145-147.

5. Bouwmeester H. 2009. Review of health safety aspects of nanotechnologies in food production. Regul Toxicol Pharmacol 53: 52-62.

6. Brehme W. 2009. Nanotecnología para mejorar la sanidad de las aves. Portal Vet Chile 20-8-09. On line: http:// www.veternet.cl/nuke/modules.php?name=News\&file $=$ article\&sid $=2584$.

7. Carlevaro M. 2007. Nanotubos contrabandean moléculas anti-HIV dentro de células. CienciaNet. On line: http:// ciencianet.com.ar/art-culos/nanotecnolog.

8. Center for Biological and Environmental Nanotechnology. 2009. Radio waves fire up nanotubes embedded in tumors, destroy liver cancer. On line: http://cben. rice. edu/uploadedImages/About/PlasmonicTherapy. bmp\&imgrefurl.

9. Cintas Izarra1 LM. 2006. Nanotecnología: la revolución industrial del siglo XXI. Online: http://weblogs.madrimasd.org/alimentacion/archive/2009/03/29/37553.aspx.

10. Cordis E. 2008. Nanotecnología y pruebas con animales. On line: http://cordis. europa.eu/fetch?CALLER=ES_NE WS\&ACTION $=$ D\&SESSION $=\&$ RCN $=29101$. 
11. Feneque J. 2003. Brief introduction to the veterinary applications of nanotechnology. Nanotechnology Now. On line: http://www.nanotech-now.com/ Jose-Feneque/Veterinary-Applications-Nanotechnology.htm.

12. Ganta C, Shi A, Battina SK, Pyle M, Rana S, Hua DH, Tamura M, Troyer D. 2008. Combination of nanogel polyethylene glycol-polyethylenimine and 6(hydro-xy1-methyl)-1,4-anthracenedione as an anticancer nanomedicine. J Nanosci Nano-technol 8: 2334-2340.

13. Gazit E. 2006. Nanotubos peptídicos que dan lugar a nanocables coaxiales. Nanotech Web. On line: http://www. euroresidentes.com/Blogs/nanotecnologia/2006 /08/nanotubos-peptdicos.html.

14. Greenwood DL, Dynon K, Kalkanidis M, Xiang S, Plebanski M, Scheerlinck JP. 2008. Vaccination against foot-and-mouth disease virus using peptides conjugated to nano-beads. Vaccine 26: 2706-2713.

15. Instituto Nacional de Tecnología Industrial (INTI). 2007. Nanotecnología. On line: http://www.inti.gov.ar/pdf/intinanotecnologia.pdf.

16. Kotov N. 2008. Ropa inteligente. On line: http://www.euroresidentes.com /Blogs/noticias-nano/2008/12/ropa-inteligente.html.

17. Lawton J. 2008. Se requieren más estudios sobre los riesgos de la nanotecnología. On line: http://www.euroresidentes.com/Blogs/noticias-nano/2008/11/se-reclamanms-estudios-sobre-los.html.

18. Lee SM, Grass G, Kim GM, Dresbach C, Zhang L, Gösele U, Knez M. 2009. Low-temperature $\mathrm{ZnO}$ atomic layer deposition on biotemplates: flexible photocatalytic $\mathrm{ZnO}$ structures from eggshell membranes. Phys Chem Chem Phys 11: 3608-3614.

19. Lerner B, Pérez M. 2009. Nanotecnología: en Argentina se desarrolla un detector temprano de cáncer. Diario Hoy (La Plata, Argentina), marzo 14, p. 6.
20. López J. 2007. Nanotecnología y producción animal. On line: http://www. diariodigitalagrario.net/versiones/rc2/ articulo2.asp?id=37374.

21. Marsagishvili LG, Bobylev AG, Shpagina MD, Troshin PA, Podlubnaia ZA. 2009. Effect of fullerenes C60 on the amyloids of X-protein. Biofizika 54: 202-205.

22. Mistry A, Stolnik S, Illum L. 2009. Nanoparticles for direct nose-to-brain delivery of drugs. Int $J$ Pharm 6: 23-27.

23. Modi S, Goswami D, Gupta GD, Mayor S, Krishnan Y. 2009. A DNA nano-machine that maps spatial and temporal $\mathrm{pH}$ changes inside living cells. Nat Nanotechnol 4: 325-330.

24. Narducci D. 2007. An introduction to nanotechnologies: what's in it for us? Vet Res Commun Suppl 1: 131-137.

25. Park B. 2008. Nanotecnología para detectar bacterias en los alimentos. On line: http://www.euroresidentes.com/ Blogs/noticias-nano/2008/12/nanotecnologa-para-detectar-bacterias.html.

26. Pérez LA, Rubiales D. 2009. Nanotechnology for parasitic plant control. Pest Manag Sci 65: 540-545.

27. Savanachi E. 2009. Agricultura muito além da vista. Agrotecnología: 42. On line: http://www.terra.com.br.

28. Schmid K, Riediker M. 2008. Use of nanoparticles in Swiss industry: a targeted survey. Environ Sci Technol 42: 2253-2260.

29. Scott NR. 2007. Nanoscience in veterinary medicine. Vet Res Commun Suppl 1: 139-144.

30. Waldner JB. 2008. Nanocomputers and swarm intelligence, Wiley \& Sons, London, p.172.

31. Yong KT. 2009. Mn-doped near-infrared quantum dots as multimodal targeted probes for pancreatic cancer imaging. Nanotechnology 20: 151-162. 